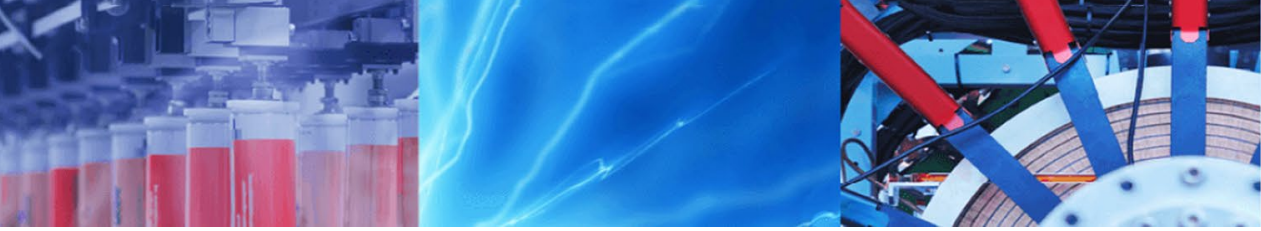

Research Article

\title{
Quantifying and addressing uncertainties in empirical vibration attenuation relationship for underground blast by re-sampling
}

\author{
Saha Dauji ${ }^{1,2}$ \\ (c) Springer Nature Switzerland AG 2019
}

\begin{abstract}
For efficient and timely execution of deep excavations, tunnelling or mining activities in rock, controlled blasting often becomes essential. For design of the controlled blasting operation, scaled distance regression analysis of trial blast data, namely, distance, charge weight, and peak particle velocity (PPV), is the regular industrial practice. Due to limited number of input data from trial blasts, and further due to variability of underlying media, multiple uncertainties creep into expressions thus developed. To account for these uncertainties in design of safe controlled blasting, therefore, 95 percent confidence expression obtained from trail blast data is generally preferred in industry. However, this approach lacks statistical quantification or treatment of the parameter uncertainty and there is no methodology suggested in literature, codes or standards to address this aspect. The present article proposes to estimate the parameter uncertainties in the empirical vibration attenuation relationship for underground blast using re-sampling approach. With blast data from literature, multiple samples are randomly selected and empirical parameters are evaluated for each set by least square principle. It is found that both empirical parameters in power form of expression (popular in industry) follow Normal distribution. Using the 95 percentile value for each parameter, the safe charges are calculated and thereafter are compared to the traditional industrial practice of employment of 95 percent confidence expression from trail blast data. Re-sampling approach yielded conservative charge weight for lower limiting values (PPV $\leq 15 \mathrm{~mm} / \mathrm{s}$ ) and efficient charge weights for higher limiting values (PPV $\geq 50 \mathrm{~mm} / \mathrm{s}$ ) of PPV.
\end{abstract}

Keywords Blast-induced ground vibration · Scaled distance regression analysis · Safe charge weight · Uncertainty . Re-sampling

\section{Introduction}

Empirical vibration attenuation relationship for underground blasts are developed from trial blast data and subsequently used for design of controlled blasting operation for various applications such as deep excavations, tunnelling, and mining. There have been several studies in recent past $[3,7,23,30,31,38,39]$ enumerating the various applications and improvements thereof for fitting empirical equations to the blast variables, namely, charge weight, monitoring distance and peak particle velocity (PPV). Furthermore, artificial intelligence (Al) tools such as artificial neural network [14, 21, 22, 28, 29, 33], random forest algorithm [17], support vector machines [17], fuzzy logic, gene expression programming [8], analytical hierarchy process $[13]$, and other tools $[20,24]$ have been employed to develop better models for the underground blasts. Whatever may be the tool employed for development of the empirical model, the performance of the models would be affected by various uncertainties involved in the process. The uncertainties would include those arising from the representativeness of the dataset, accuracy of estimated parameters, suitability of the expression form between scaled distance and PPV, effect of rock discontinuities, rock

Saha Dauji, acad.dauji@gmail.com; dauji_saha@yahoo.com | ${ }^{1}$ NRB Office, Bhabha Atomic Research Centre, Mumbai 400094, India. ${ }^{2}$ Homi Bhabha National Institute, Mumbai 400094, India. 
stratification, rock types, rock formation, rock joints and their orientation, presence of water table, soil-rock interface, acoustic behaviour of rocks, explosive type, and other details of blasting operation.

The traditional approach generally adopted to account for the various uncertainties involved in the empirical vibration relationships of underground blasts is to use the 95 percent confidence expression based on the trial blast data. Such strategy was reported in literature $[38,39]$ for design of controlled blasting operation. When critical structures/facilities are involved, more stringent (greater than 95 percent) equations might be used. Agrawal and Mishra [3] reported a study wherein they attempted to modify the equation (derived for single-hole blast data) for design of multi-hole blasting operation, using some multihole blasting data and additional empirical parameter. However, all these empirical approaches are ad-hoc and lack sound statistical foundation towards quantification of or accounting for-the various uncertainties involved.

More specific treatments of uncertainty in blast effects reported in recent literature are few. In addition to the uncertainties in other variables such as bit life and operating costs, Abbaspour et al. [1] considered uncertainties of rock density and uniaxial compressive strength of rock in optimization of the integrated drilling and blasting operation involved in open cast mines. Agrawal and Mishra [2] presented a probabilistic treatment of the scattering effect of different initiation systems for blast induced ground vibrations. McMullan and Collins [18] quantified uncertainty in continuous fragmentation air burst fragments with multiple numerical models. Stewart and Netherton [37] presented quantitative explosive risk assessment concept for robust method of accounting for blast-load and fragment variability. The most relevant study was by Murmu et al. [25] in which the authors adopted Monte Carlo simulation approach for probabilistic study of blast induced ground vibration using empirical relationship. Probability density functions were defined for the input variables and the exceedance probability of a certain limiting PPV was estimated under probabilistic framework as the final outcome of the study. However, none of the aforementioned studies suggested methodology for quantification or accounting for the parameter uncertainty involved in routine controlled blasting operation.

There are two broad categories of uncertainties-aleatory and epistemic $[6,19,40]$. Aleatory uncertainty pertains to natural randomness inherent to the process whereas epistemic uncertainty represents the scientific uncertainty in the model of the process [16]. While the former is irreducible, the latter is considered reducible, with better knowledge of the process [16]. However, in most practical cases, it becomes difficult to segregate the uncertainties into the two categories. Various methods for handling the uncertainties in the experimental data including statistical approaches such as Re-sampling, Monte Carlo simulation or Bayesian method as well as Al approaches such as neural network and fuzzy logic have been discussed in literature $[5,11,35]$. In the present case of estimate of blast variables for underground blasts, the various uncertainties involved may be the inherent variability of the ground response to underground blast, the variability of the soil properties in the area, the measurement errors from the trial blasting, the choice of location of the blast and measurements, the selected model and the estimated parameters. In the past, investigators have suggested methods for choice of best fitting empirical model for underground blast [7]. Whatever may be the best suited expression (generally the power form of expression is preferred for modelling vibration induced by underground blasts in industry), the estimated parameters would depend on the trial blast data. However, as mentioned earlier, the assessment of the parameter uncertainties of the empirical blast relationship have rarely been conducted specifically, nor are methodologies available to account for the same, particularly for the design of safe controlled blasting operations. Part of the parameter uncertainty of such expressions might be epistemic, i.e. due to the limited data used for estimation of the parameters, and hence might get reduced with augmentation of trial blast data. On the other hand, part of the parameter uncertainty could be aleatory, i.e. owing to the inherent randomness of the rock media properties, and its particular response to the blast. Categorising the parameter uncertainty (focus of the present study) would thus be difficult, but methods can be devised for quantification and addressing this parameter uncertainty.

The fundamental postulate for data-driven approaches is that the various characteristic features and the uncertainties of the variables of the problems are embodied in the data, which are reflected in the parameters of the empirical relationship established from the data. In this article, it is postulated that the various uncertainties for the different variables for underground blasting are represented by the uncertainties of the empirical parameters of the vibration attenuation relationship. Studies pertaining to quantification the uncertainties in the empirical parameters for the vibration attenuation relationship in case of underground blasts or addressing them are scarce in literature. Generally, the industrial practice is to adopt the 95 percent confidence curve for the vibration attenuation relationship and design the controlled blasting with that $[38,39]$. But this approach lacks a firm statistical foundation. In this regard, re-sampling approach could be very useful tool for quantification and addressing the uncertainty of the empirical blast parameters. Re-sampling techniques have been gainfully utilized for addressing the uncertainties in a variety of problems, such as, population 
projections [9], estimation of fluvial suspended sediment loads [32], extreme value analysis in ocean engineering [15], hydrological frequency analysis [12], hydrological predictions [36], estimation of time travel uncertainty [26], and rainfall depth-duration-frequency (DDF) curves [27].

In hydrology, similar uncertainty quantification of empirical expression of variables was reported by Rustomji and Wilkinson [32] wherein the authors addressed the unexplained variance in the inputs as well as the shape of the rating curve (expression form for the relationship) by adopting bootstrap re-sampling methodology. It was indicated that the similar approach could be applicable for accounting for the uncertainties of empirical expressions for other variables or other expression forms. This was essentially achieved by using bootstrap samples from the available data and estimation of the regression parameters for them, thereafter the suite of generated curves were used to quantify the uncertainty of the fitted rating curve (expression). So far as the subsurface uncertainty is concerned, application adopting re-sampling approach for addressing the uncertainty in estimates is rare in literature. One recent application towards mapping of imbalanced soil classes [34] employed re-sampling approach along with Markov chain random field models.

As discussed earlier, the standard industrial practice of adopting the 95 percent confidence curve for the vibration attenuation modelling and design of controlled blasting lacks a rigorous statistical treatment for addressing the parameter uncertainty. To the knowledge of the author, better methodology for addressing parameter uncertainty in blast models is presently not available in literature, code or standards. The present article attempts to fill this gap and proposes a methodology, which would be very useful for design of safe controlled blasting by practicing blast designers. It would later emerge that the proposed methodology could be more efficient compared to the present industrial practice in certain cases. Towards this, the objectives of this article are identified as: quantification of the uncertainty of parameters of empirical vibration relationship for underground blast under statistical framework (using re-sampling approach); and estimation of safe charge weight for a particular confidence level, accounting for the uncertainties quantified earlier. The proposed methodology would have to be suitable for application on a finite dataset (here 39 sets) as trial blast results are limited in number. The uncertainty in estimation of PPV using empirical expressions can be broadly classified as input uncertainty, parameter uncertainty, measurement error/output uncertainty, and uncertainty in model structure-in addition to the inherent randomness of the variables involved in the process. In this article the proposed procedure of quantification of uncertainties would cover two aspects: input/output uncertainty and parameter uncertainty. The re-sampling approach is proposed to be employed for quantification of these uncertainties. The development of the empirical blast vibration relationship is targeted towards arrival at safe charge weight corresponding to the safe limiting PPV and distances involved. The uncertainties are addressed towards this objective by first establishing the probability density function for the empirical parameters, thereafter estimating the values of the empirical parameters for the confidence level desired and subsequently estimation of the safe charge weights for varying distances for the respective limiting safe PPV values. The estimates arrived at in the proposed method are compared to the traditional industrial practice of adopting the 95 percent confidence expression for the safe charge weight estimation and the relative merits are discussed. The application of the proposed methodology would be for design of controlled blasting for deep excavations/tunnelling or mining, and the implementation steps for the same have been elucidated in the end.

\section{Data and methodology}

For this study, the data has been taken from literature [3]. In their study, the authors reported the multi-hole blast data from production blasting (39 sets, in Table 2 of the referred article) and test blasting operation ( 9 sets, in Table 4 of the referred article).

The square root scaled distance (Eq. 1) was used by the authors and the same has been adopted in this study.

$S D=\frac{D}{\sqrt{Q}}$

where $S D$ Scaled Distance $\left(\mathrm{m} / \mathrm{kg}^{0.5}\right) ; D$ Distance $(\mathrm{m}) ; Q$ Charge Weight (kg).

The dataset consisting of scaled distance (SD) and measured peak particle velocity (PPV) pairs from the production blast and test blast operations [3] is reproduced in Table 1 for ready reference. The production blast data containing 39 sets of values are used for model development in this study and the test blast data consisting of 9 sets of values is used for model evaluation purposes. The statistical properties of the charge weight $(Q: \mathrm{kg})$, distance $(D: \mathrm{m})$ of measurement point from blast location, scaled distance (SD: $\mathrm{m} / \mathrm{kg}^{0.5}$ ) and the measured peak particle velocity (PPV: $\mathrm{mm} / \mathrm{s}$ ) are listed in the Table 2 for easy reference. For all the input variables, the mean and median are quite close, indicating symmetry in distribution. For the output variable, for both datasets, the mean is higher than the median, indicating higher number of lower values. The variability associated with the variables, except charge weight, are quite high (34-92\%) for modelling dataset. The evaluation 
Table 1 Scaled distance and PPV for production blast (39 sets) and test blast (9 sets)

\begin{tabular}{|c|c|c|c|c|c|c|c|}
\hline \multicolumn{6}{|c|}{ Production blast: modelling set } & \multicolumn{2}{|c|}{ Test blast: evaluation set } \\
\hline $\begin{array}{l}\text { Scaled distance } \\
\left(\mathrm{m} / \mathrm{kg}^{0.5}\right)\end{array}$ & $\mathrm{PPV}(\mathrm{mm} / \mathrm{s})$ & $\begin{array}{l}\text { Scaled distance } \\
\left(\mathrm{m} / \mathrm{kg}^{0.5}\right)\end{array}$ & $\mathrm{PPV}(\mathrm{mm} / \mathrm{s})$ & $\begin{array}{l}\text { Scaled distance } \\
\left(\mathrm{m} / \mathrm{kg}^{0.5}\right)\end{array}$ & $\mathrm{PPV}(\mathrm{mm} / \mathrm{s})$ & $\begin{array}{l}\text { Scaled distance } \\
\left(\mathrm{m} / \mathrm{kg}^{0.5}\right)\end{array}$ & $\mathrm{PPV}(\mathrm{mm} / \mathrm{s})$ \\
\hline 7.071 & 23.420 & 14.142 & 8.378 & 21.651 & 2.667 & 10.787 & 10.865 \\
\hline 7.217 & 21.600 & 14.142 & 9.652 & 22.627 & 3.937 & 11.429 & 9.56 \\
\hline 7.217 & 25.530 & 14.434 & 10.920 & 23.094 & 1.963 & 11.926 & 8.98 \\
\hline 7.454 & 20.890 & 16.181 & 3.909 & 24.042 & 1.778 & 16.181 & 5.46 \\
\hline 8.485 & 13.260 & 16.971 & 6.668 & 25.456 & 3.302 & 17.143 & 4.367 \\
\hline 9.449 & 16.400 & 16.971 & 6.350 & 25.981 & 2.032 & 17.889 & 3.98 \\
\hline 10.104 & 11.180 & 17.321 & 3.112 & 26.726 & 1.842 & 24.271 & 2.67 \\
\hline 10.787 & 10.850 & 17.889 & 3.556 & 26.968 & 0.699 & 25.714 & 2.89 \\
\hline 11.547 & 7.086 & 17.889 & 6.096 & 26.968 & 1.016 & 26.833 & 2.065 \\
\hline 12.990 & 8.255 & 20.045 & 2.081 & 28.347 & 3.048 & - & - \\
\hline 13.484 & 8.890 & 20.870 & 4.191 & 28.347 & 4.445 & - & - \\
\hline 13.484 & 8.000 & 21.574 & 1.016 & 28.868 & 2.413 & - & - \\
\hline 13.484 & 6.376 & 21.651 & 1.397 & 33.408 & 1.397 & - & - \\
\hline
\end{tabular}

Table 2 Statistical properties of blast variables for production blast (39 sets) and test blast ( 9 sets)

\begin{tabular}{|c|c|c|c|c|c|c|c|c|}
\hline \multirow[t]{2}{*}{ Statistic } & \multicolumn{4}{|c|}{ Production blast: modelling set } & \multicolumn{4}{|c|}{ Test blast: evaluation set } \\
\hline & $\begin{array}{l}\text { Charge } \\
\text { weight }(\mathrm{kg})\end{array}$ & Distance (m) & $\begin{array}{l}\text { Scaled dis- } \\
\text { tance }\left(\mathrm{m} / \mathrm{kg}^{0.5}\right)\end{array}$ & $\mathrm{PPV}(\mathrm{mm} / \mathrm{s})$ & $\begin{array}{l}\text { Charge } \\
\text { weight }(\mathrm{kg})\end{array}$ & Distance (m) & $\begin{array}{l}\text { Scaled dis- } \\
\text { tance }\left(\mathrm{m} / \mathrm{kg}^{0.5}\right)\end{array}$ & $\mathrm{PPV}(\mathrm{mm} / \mathrm{s})$ \\
\hline Mean & 48.67 & 125.64 & 18.09 & 7.17 & 49.67 & 126.67 & 18.02 & 5.65 \\
\hline Median & 50.00 & 120.00 & 17.32 & 4.45 & 49.00 & 120.00 & 17.14 & 4.37 \\
\hline SD & 6.96 & 50.72 & 7.22 & 6.57 & 4.36 & 43.59 & 6.26 & 3.31 \\
\hline $\begin{array}{l}\text { Coefficient of } \\
\text { variation }\end{array}$ & 0.14 & 0.40 & 0.40 & 0.92 & 0.09 & 0.34 & 0.35 & 0.59 \\
\hline Maximum & 56.00 & 250.00 & 33.41 & 25.53 & 55.00 & 180.00 & 26.83 & 10.87 \\
\hline Minimum & 28.00 & 50.00 & 7.07 & 0.70 & 45.00 & 80.00 & 10.79 & 2.07 \\
\hline
\end{tabular}

dataset has less variability compared to the modelling dataset for the respective variables. The ranges involved in the evaluation dataset are generally contained within the modelling dataset, and thereby the evaluation results are expected to be within model domain. Further information of the actual operation of the blasting and other details can be obtained from the literature [3].

The traditional expression favoured by most researchers and industrial applications is the power form (Eq. 2).

$P P V=a \times(S D)^{b}$

where $a, b$ empirical parameters;

The parameters of traditional power form of expression (Eq. 2) were estimated from the modelling dataset by least square principle [4] and were thereafter compared to the equation given for the same data in literature [3] for accuracy. Multiple performance metrics were used for evaluation of different aspects of performance of the empirical constants from this study and those from literature. They are the correlation coefficient, root mean square error (RMSE) and mean absolute error (MAE) evaluated for either expression. The correlation coefficient signifies the linear association of the two variables, MAE indicates the overall error on the absolute scale, whereas RMSE is more sensitive to the errors at the extremes. Variable plots and scatter plots helped in qualitative evaluation of the expressions.

In development of these empirical models, the complex non-linear conditions existing at the site reflected in the measured PPV values are assumed to be represented by the single variable: scaled distance. The empirical parameters fail to account for the various uncertainties involved, which results in the inaccuracies of the models. As a regulatory requirement, there are limiting PPV which should not be exceeded during the controlled blasting operation. The various limiting values of PPV suggested for different conditions stipulated in Indian codes (IS 6922, IS 14881) were summarized by Ray and Dauji [30]. The regular practice in the industry for catering to the uncertainty of the 
equation developed from trial blast data is adopting the 95 percent confidence expression from the trial blast data for the design of controlled blasting operation.

However, such expressions are totally dependent on the data from which they are derived and lack statistical foundation and consequently, the quantification of the uncertainties involved is not available. In this study, a new approach is proposed to quantify and account for the various uncertainties is estimation of the empirical parameters based on the re-sampling methodology [40]. Random samples are drawn from the modelling dataset (containing a total of 39 data pairs), each of $n$ data pairs. In this study, it is suggested to use $n$ as 30, i.e. 30 data pairs for each sample. The value of $n$ was varied as 25,30 , and 35 in order to evaluate the effect of the number of data pairs around the suggested value of 30 , on the empirical parameters. For each case of data pairs (value of $n$ ), 30 samples were drawn and the empirical model parameters ( $a, b$ of Eq. 2 ) were estimated. Higher number of sample sets might be taken for this exercise, and here it has been performed for the basic minimum number of 30 samples. Probability density function was fitted for the samples of the parameters ( $a, b$ of Eq. 2 ) and the goodness of fit was evaluated by Chi square and Kolmogorov-Smirnov $(\mathrm{K}-\mathrm{S})$ tests. For the probability distributions, goodness of fit tests, and other statistical details, standard textbooks may be referred $[4,10,40]$.

The quantification of uncertainty of the empirical equations for underground blasts has been performed with two considerations. The coefficient of variation (COV) of the empirical parameters obtained from the samples would signify the degree of uncertainty of the respective best estimate (mean) value of the empirical parameter. The mean squared error of estimated PPV obtained from the samples would indicate the overall degree of errors of the estimates, i.e. the uncertainty of the output PPV obtained from the empirical equation.

The parameter uncertainty of the developed empirical expressions was addressed for estimation of safe charge weight as follows. The mean and the 95 percent confidence values of each parameter were estimated using statistical properties of the probability density functions established earlier. These values were thereafter utilised to establish the mean expression and the 95 percent confidence expression for vibration attenuation relationship. The mean and the 95 percent confidence expressions developed in the proposed approach are subsequently compared to the corresponding ones obtained by the traditional industrial practice with the data from the evaluation set (Table 1). The various limiting values of PPV listed by Ray and Dauji [30] were adopted and for the limiting PPV of $5 \mathrm{~mm} / \mathrm{s}, 15 \mathrm{~mm} / \mathrm{s}, 50 \mathrm{~mm} / \mathrm{s}, 75 \mathrm{~mm} / \mathrm{s}$, and $100 \mathrm{~mm} / \mathrm{s}$, the 95 confidence expressions evaluated by both the traditional approach and proposed approach are presented and the results are compared.

\section{Results and discussions}

\subsection{Development of traditional mean and 95 percent confidence relationship for the site}

The equation developed in this study from modelling data (Table 1) adopting the expression form of Eq. 2, is given in Eq. 3 and that reported in literature [3] for the same dataset is reproduced as Eq. 4 for ready reference.

$P P V=726.258 \times(S D)^{-1.75603}$

$P P V=1018 \times(S D)^{-1.909}$

Possibly due to the difference in method of estimation of empirical parameters, the values of ' $a$ ' and ' $b$ ' estimated in this study were different from those reported by Agrawal and Mishra [3]. However, the performance ascertained with the error metrics for either equation (Eqs. 3 and 4) was similar (Table 3 discussed in Sect. 3.2), which was also reflected in the variable plots and scatter plots (Figs. 1 and 2) for the two expressions.

As can be observed in the variable and scatter plots (Figs. 1 and 2), there is a certain degree of inaccuracy in the estimates of PPV from empirical models. The traditional approach is adopted here and the 95 percent confidence expression is derived in the form of Eq. 5, from Eq. 3 obtained earlier.
Table 3 Performance of Eqs. 3 and 4 for production blast (39 sets) and test blast ( 9 sets)

\begin{tabular}{lllllll}
\hline Dataset & Expression & $a$ & $b$ & $\begin{array}{l}\text { Correlation } \\
\text { coefficient }\end{array}$ & RMSE (mm/s) & MAE (mm/s) \\
\hline Production blast (39 sets) & Equation 3 & 726.258 & -1.75063 & 0.966 & 1.679 & 1.374 \\
& Equation 4 & 1018 & -1.909 & 0.965 & 1.738 & 1.414 \\
\multirow{2}{*}{ Test blast (9 sets) } & Equation 3 & 726.258 & -1.75063 & 0.966 & 0.399 & 0.336 \\
& Equation 4 & 1018 & -1.909 & 0.996 & 0.349 & 0.250 \\
\hline
\end{tabular}

Results of this study are given in italics (Eq. 3) and compared with the results of the corresponding expression (Eq. 4) from literature [3] 


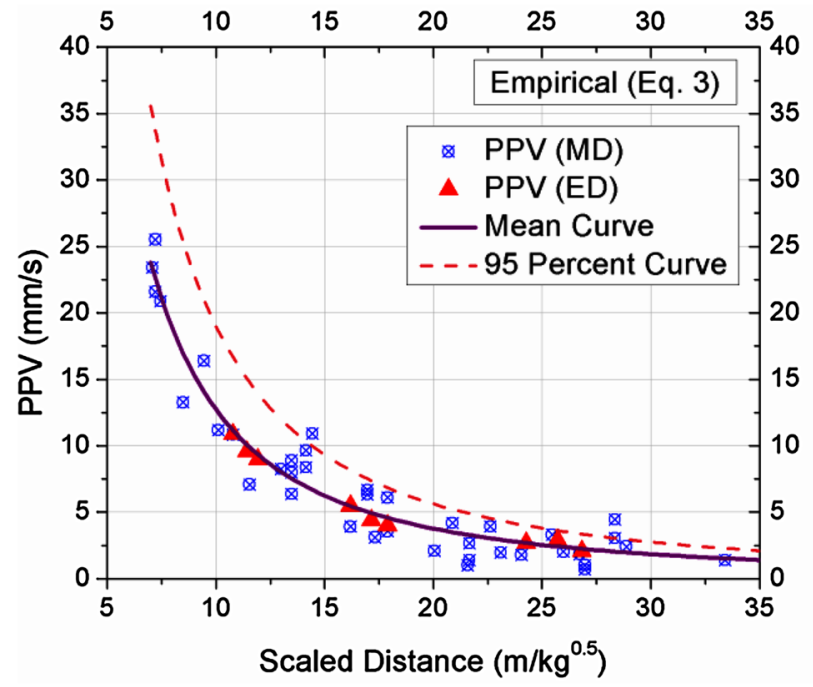

(a)

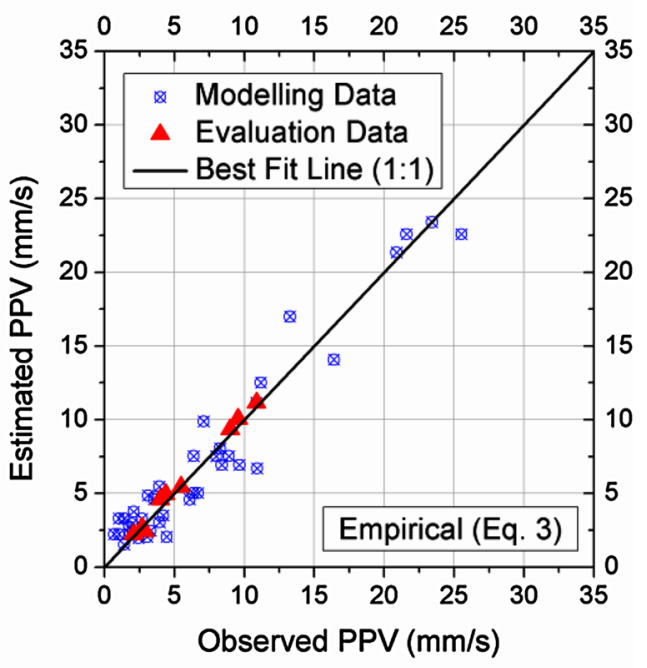

(b)

Fig. 1 Performance of Eq. 3 (present study). a Variable plot: mean and 95 percent confidence, $\mathbf{b}$ scatter plot: mean (MD modelling data, ED evaluation data)

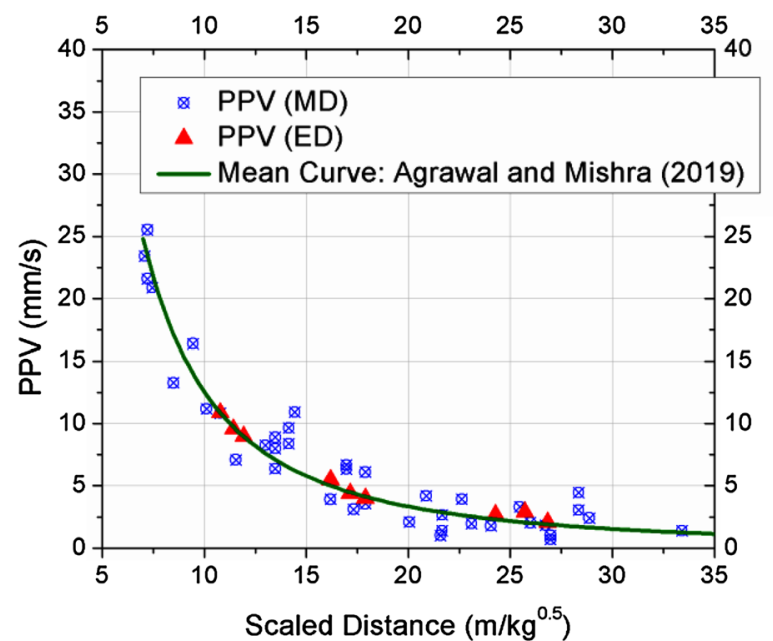

(a)

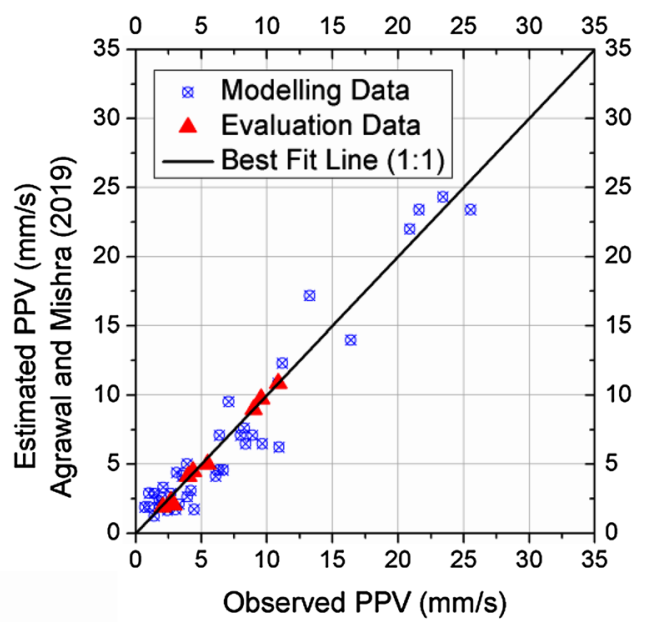

(b)

Fig. 2 Performance of Eq. 4: Agrawal and Mishra [3]. a Variable plot: mean, b scatter plot: mean (MD modelling data, ED evaluation data)

$P P V=1085 \times(S D)^{-1.75603}$

As can be noted from Fig. 1a, only 2 out of 39 cases ( $~ 5 \%$ ) of the estimates fall short of the observed PPV values for modelling dataset and none for the evaluation dataset. This was indicated earlier that as the ranges of the variables in the evaluation dataset were included in the corresponding ranges of modelling dataset and the variability was less for the former, the results expected for the evaluation dataset was good.

\subsection{Performance comparison of mean expression developed in this study (Eq. 3) and expression from literature (Eq. 4)}

The performance of the Eq. 3 developed in this study and the Eq. 4 [3] is compared in Table 3 with correlation coefficient, RMSE and MAE. From the comparison, it might be inferred that though the empirical parameters are quite different for the expressions (Eqs. 3 and 4), their 
performance is comparable for both the modelling set and the evaluation set. The variable and scatter plots (Fig. 1) show a good fit of the Eq. 3 with the experimental data. Hereafter, the Eq. 3 developed in this study is used in lieu of the traditional estimate for comparison purposes. The 95 percent confidence expression developed on the basis of Eq. 3 and traditional principles was presented as Eq. 5 and the respective underestimations by Eq. 5 for the modelling set and the evaluation set were $5 \%$ and $0 \%$, as can be observed in Fig. 1a. Adopting traditional industrial practice, controlled blasting operations could be designed based on Eq. 5 .

\subsection{Statistical properties of the empirical parameters ' $a$ ' and ' $b$ ' obtained from re-sampling and quantification of uncertainty in parameters and estimates}

As described in the methodology section, 30 samples, each consisting of 30 data pairs, were drawn from the 39 data pairs of modelling set. For each sample, the empirical parameters ' $a$ ' and ' $b$ ' for Eq. 2 were evaluated by least square principle. Thus, 30 values were obtained for each of the parameters (' $a$ ' and ' $b$ ') with 30 data pairs. Similarly, the exercise was repeated for 25 and 35 data pairs. The various percentiles are marked in the box and whisker plots (Fig. 3) presented for the two empirical parameters, ' $a$ ' and ' $b$ ', for the different numbers of the data pairs in each of the 30 samples from which the statistical properties are derived. The mean is marked by the small square box and the maximum and minimum are also marked in the plots. The data distribution appears somewhat symmetric and the mean and median coincide for parameter ' $a$ ' when the number of data pairs is 30 or 35 , whereas for 25 data

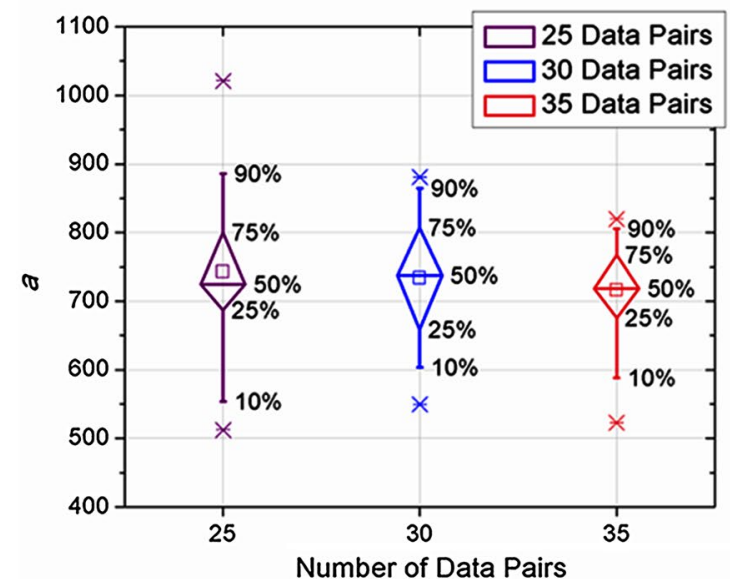

(a) pairs, it has a longer right-hand tail. For the parameter ' $b$ ', the data distributions for 30 and 35 data pairs are again similar with a longer right hand tail, whereas for the 25 data pair samples, it is longer left tail. It may be inferred that the distribution of parameters in the re-sampled sets are similar for 30 data pairs or more. Hence, it is proposed to use a sample size of 30 or more for re-sampling in this study. However, the results are presented for 25 data pairs also for comparison.

As mentioned earlier, the uncertainty of the variables are represented by the uncertainty of the empirical parameters of the relationship. Coefficient of variation (COV), which is the standard deviation of the data normalized by the mean, is an indication of the variability or uncertainty of the data. Using re-sampling approach, the COV-s for parameter ' $a$ ' were $0.150,0.125$ and 0.104 for 25,30 and 35 data pairs respectively. With increase in the number of data pairs in each sample, the COV (uncertainty) reduced, which is expected. For parameter ' $b$ ' also, similar trend was observed with the COV-s at $0.036,0.032$ and 0.026 for 25,30 and 35 data pairs respectively. The uncertainty of the parameters of the empirical expression reduced with increasing number of data in each of the re-sampled sets. However, as the number of data available from trial blasts would be limited, it is suggested to keep the minimum number of data pairs at the traditional value of 30 .

The overall modelling output uncertainty is indicated by the mean squared error of the samples obtained by re-sampling approach and the box and whisker plots for the same is presented in the Fig. 4, wherein Fig. 4a depicts the complete plot and Fig. $4 \mathrm{~b}$ shows a blow-up to better depict the data distribution for 25, 30 and 35 data pairs respectively. As is observed in the Fig. 4, 30 numbers of data pairs give the minimum range of errors, wherein

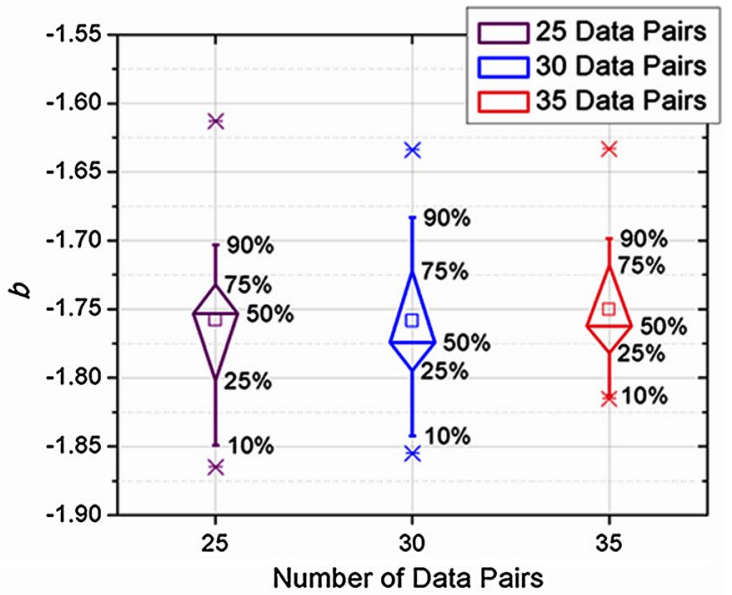

(b)

Fig. 3 Box and Whisker plots. a parameter ' $a$,' b parameter ' $b$ ' 


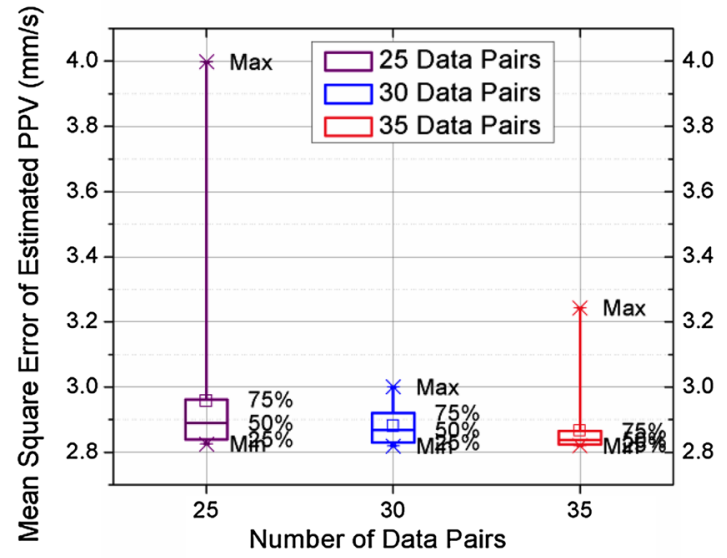

(a)

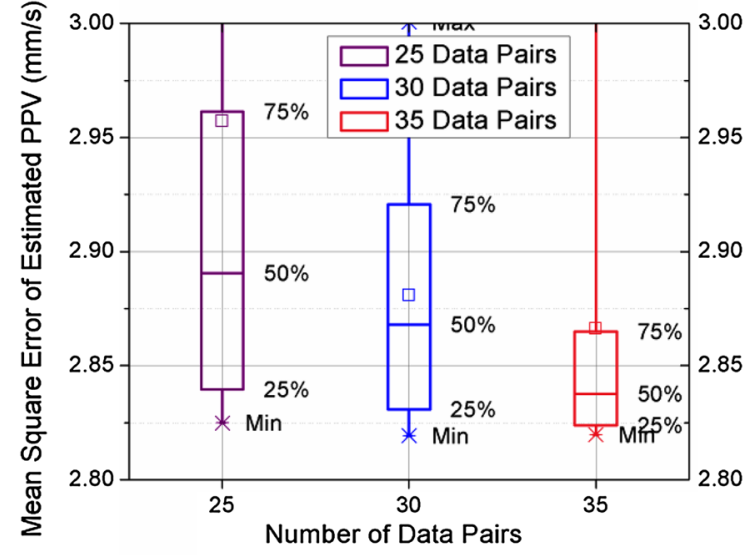

(b)

Fig. 4 Box and Whisker plots. a Mean squared error in estimated PPV (mm/s), b blow-up of (a)

the mean and median are quite close as well. Thus, the expected uncertainty of the PPV estimates from the empirical expression would be around $1.673 \mathrm{~mm} / \mathrm{s}$ and $1.732 \mathrm{~mm} / \mathrm{s}$ (the root mean squared error).

\subsection{Probability density function and goodness-of-fit for the empirical parameters}

It was found that the Normal distribution was suitable for both the parameters as checked by the Chi Square Test and Kolmogorov-Smirnov Test at standard 5 percent significance level. The histograms and the probability density functions are plotted in Figs. 5, 6 and 7 for the sample size of 25 data pairs, 30 data pairs and 35 data pairs respectiv ely.

Though the distributions do not appear to be exactly fitting the histograms, the fitted Normal density function was found to be acceptable at $5 \%$ significance level for all six sets of data. As can be easily discerned from the histograms overlaid with the probability density functions, for both the parameters, better fit has been achieved by the data set with 30 data pairs.

\subsection{Mean and 95 percent confidence expression obtained by re-sampling approach}

The mean values and the 95 percent confidence values of the parameters ' $a$ ' and ' $b$ ' are listed in Table 4 . With increasing number of data pairs in the re-sampled sets, the value of parameter ' $a$ ' as well as parameter ' $b$ ' reduced for the mean and 95 percent confidence level. The respective values of the empirical parameters obtained from traditional approach are reproduced alongside and the values for both parameters fall between the 30 data pair and 35 data pair values for the mean expression. However, for the 95 percent confidence expression, in traditional approach only the parameter ' $a$ ' is varied to fulfil the $95 \%$ criteria and hence, it is higher than any of the values obtained by the proposed approach.
Fig. 5 Probability density function: 25 data pairs. a Parameter ' $a$ ', b parameter ' $b$ '

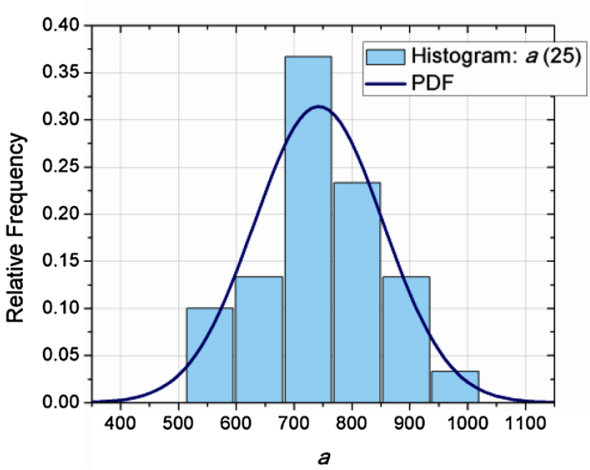

(a)

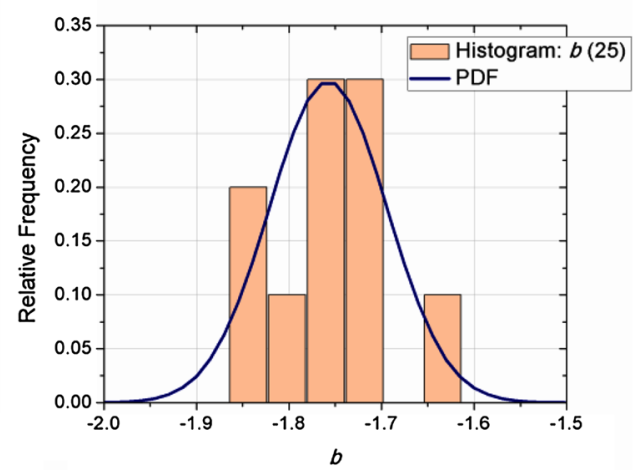

(b) 
Fig. 6 Probability density function: 30 data pairs. a Parameter ' $a$, b parameter ' $b$ '

Fig. 7 Probability density function: 35 data pairs. a Parameter ' $a$ ', b parameter ' $b$ '

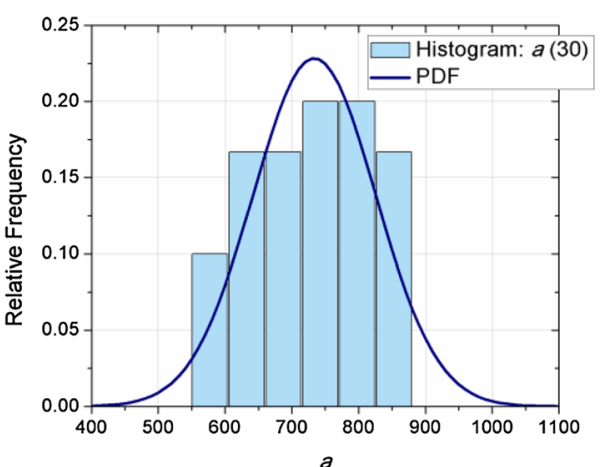

(a)

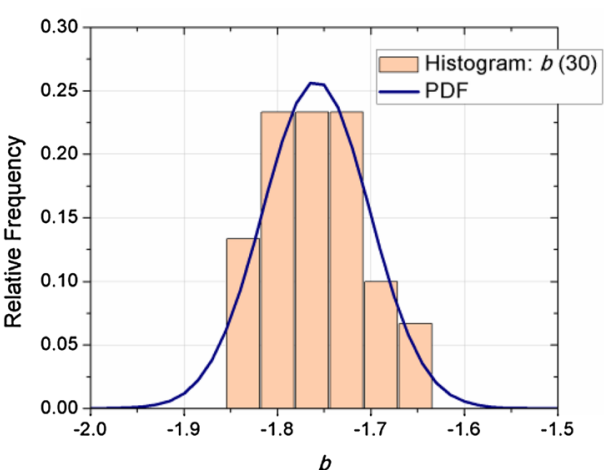

(b)

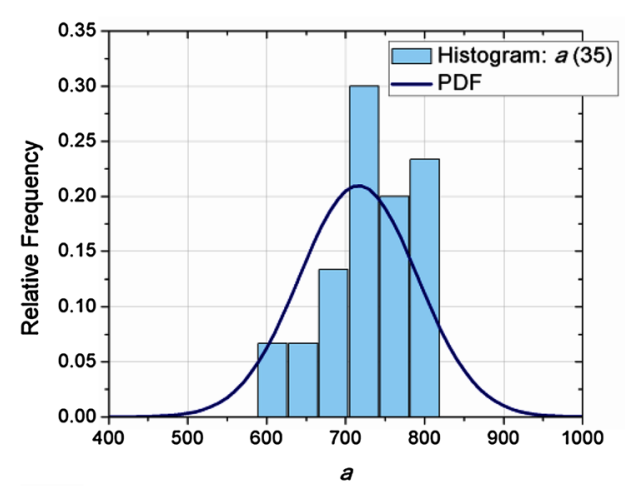

(a)

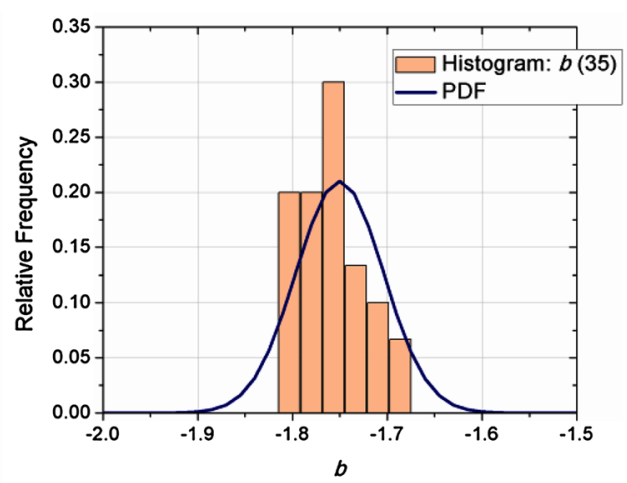

(b)

Table 4 Empirical parameters for Eq. 2 from re-sampling: mean and 95 percent confidence values

\begin{tabular}{|c|c|c|c|c|c|c|c|c|}
\hline \multirow[t]{2}{*}{ Case } & \multicolumn{4}{|l|}{$a$} & \multicolumn{4}{|l|}{$b$} \\
\hline & 25 data pairs & 30 data pairs & 35 data pairs & Emp. & 25 data pairs & 30 data pairs & 35 data pairs & Emp. \\
\hline Mean & 742.656 & 733.716 & 716.164 & 726.258 & -1.75773 & -1.75852 & -1.75032 & -1.75063 \\
\hline $\begin{array}{l}95 \text { percent } \\
\text { confidence } \\
\text { value }\end{array}$ & 926.512 & 885.460 & 839.484 & 1085 & -1.65275 & -1.66451 & -1.67417 & -1.75063 \\
\hline
\end{tabular}

Fig. 8 Performance of proposed approach ( 25 data pairs). a Variable plot, b scatter plot (mean) ( $M D$ modelling data, ED evaluation data)

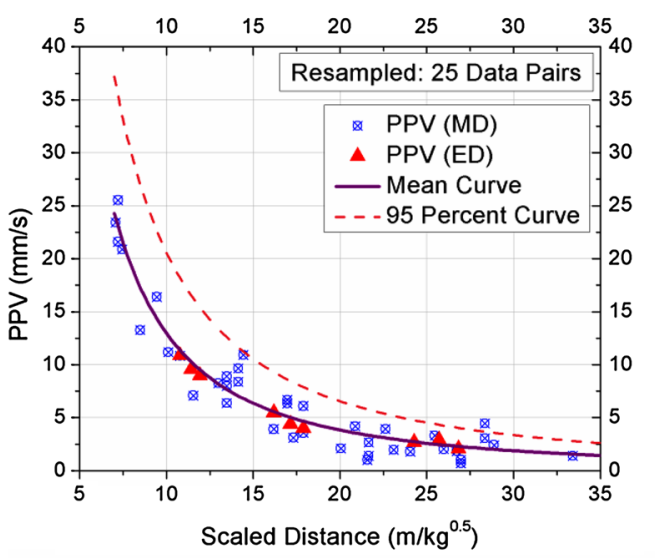

(a)

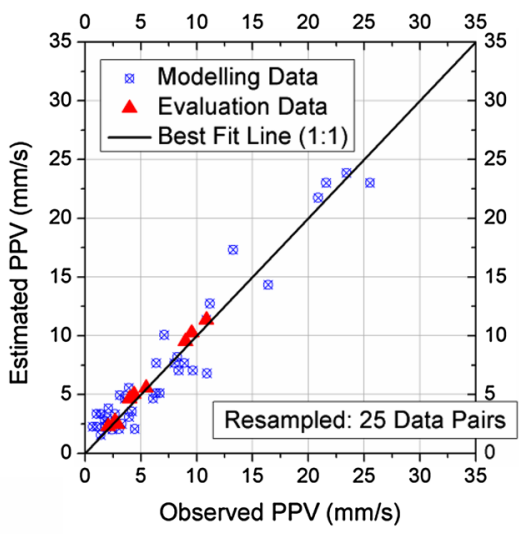

(b) 
Fig. 9 Performance of proposed approach (30 data pairs). a Variable plot, b scatter plot (mean) (MD modelling data, $E D$ evaluation data)

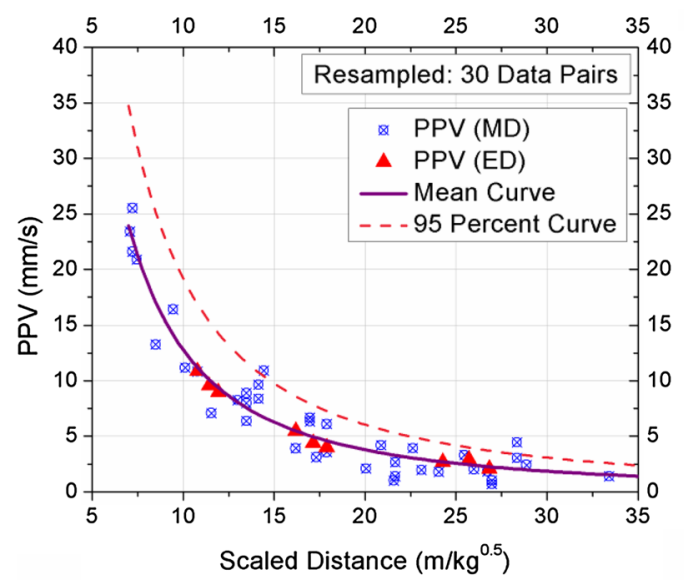

(a)

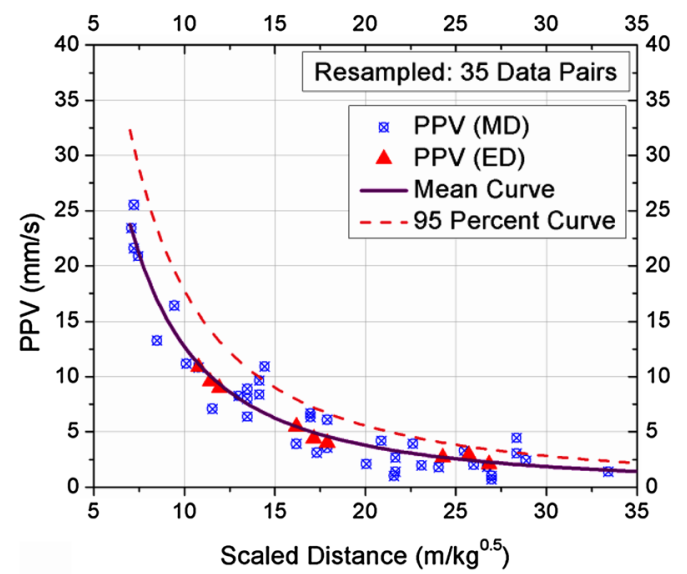

(a)

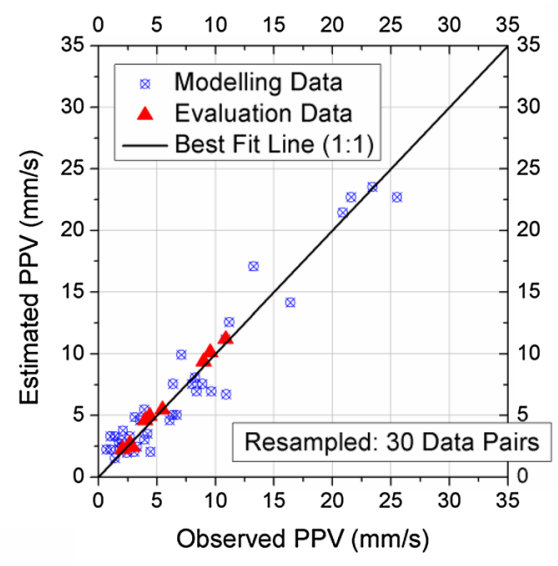

(b)
Fig. 10 Performance of proposed approach (35 data pairs). a Variable plot, b scatter plot (mean) (MD modelling data, $E D$ evaluation data)

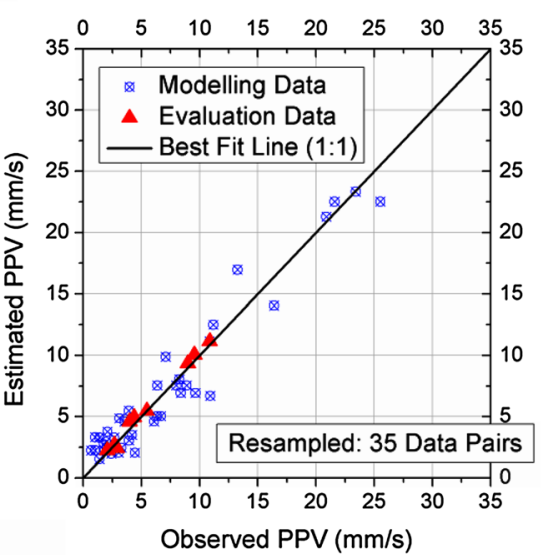

(b)
The variable plots and the scatter plots for mean for the different data pairs (25, 30 and 35 ) are presented in Figs. 8, 9 , and 10 respectively. From the figures, the gap between the mean curve and the 95 percent confidence curve is higher in the 25 data pair case and reduces as the number of data pairs in each re-sampled set increases. This is in line with the earlier observations from Fig. 3 in Sect. 3.3 wherein lower variability (uncertainty) was observed for higher number of data pairs. The empirical curves would fall somewhere in between the 30 and 35 data pair curves. It is noted that for all the three 95 percent confidence curves obtained from re-sampling, not more than two modelling data points and none of the evaluation data points fall above the curves-similar to the empirical 95 percent confidence curve discussed in Sect. 3.2. This confirms that the proposed method yields expressions which conform to the targeted confidence percentage.

The mean and the 95 percent confidence expressions are plotted together for comparison in Fig. 11a and b respectively. Whereas the mean expressions are more or less indistinguishable, there is a slight variation observed in the 95 percent confidence expressions. Particularly, if the expressions for empirical and the re-sampling with 30 data pairs are compared, it can be discerned that the traditional approach yields higher estimate of PPV for lower SD values and vice versa. The crossover happened at a value of SD around $9 \mathrm{~m} / \mathrm{kg}^{0.5}$, i.e. beyond this value, the re-sampling approach would result in establishing lower PPV estimates, and thereby higher safe charge weights for any particular limiting PPV.

\subsection{Safe charge weight from 95 percent confidence expressions: empirical and re-sampling exercise}

Presently the derivation of the safe charge for controlled blasting is explored in Fig. 12, which depicts the 30 individual expressions obtained for the different sample datasets containing 25,30 and 35 data pairs respectively for the limiting PPV of $50 \mathrm{~mm} / \mathrm{s}$. The last panel shows the superimposition of the three expressions obtained from re-sampling analysis, and alongside the empirical expression (represented by star shape) is also plotted. It should 


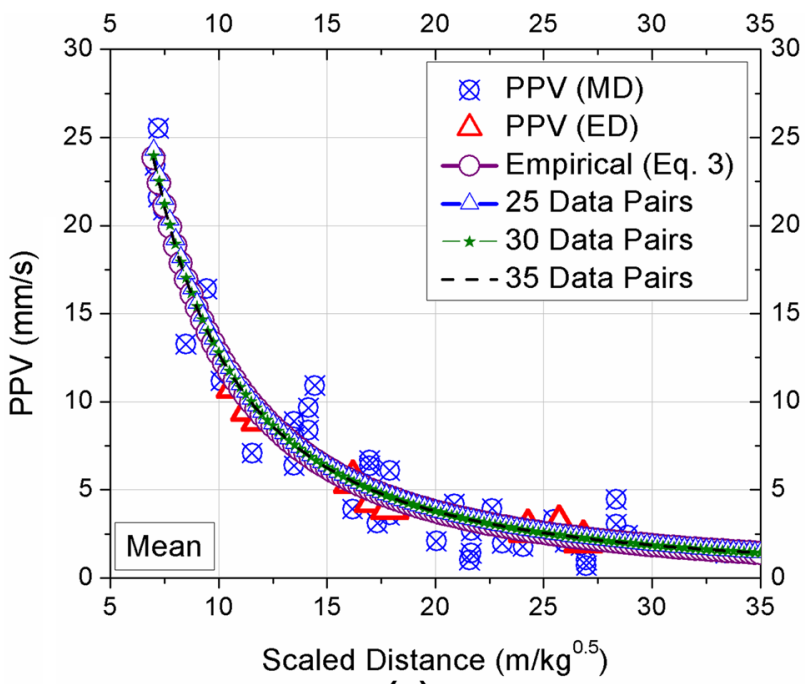

(a)

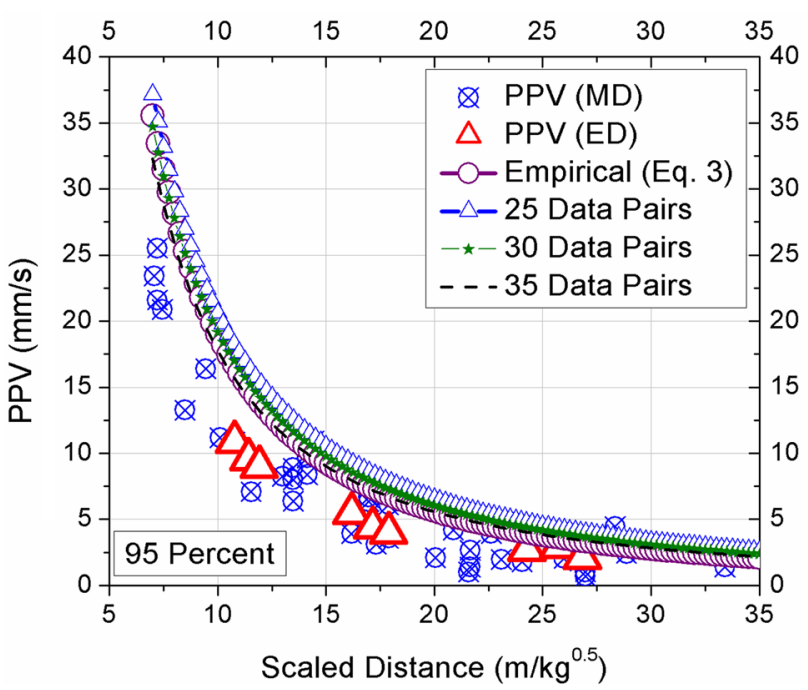

(b)

Fig. 11 Comparison of SD-PPV relationships for empirical and resampling approaches ( $M D$ modelling data, $E D$ evaluation data). a mean curve, b 95 percent confidence curve

be noted here that all these curves in Fig. $12 \mathrm{~d}$ represent the 95 percent confidence relationships, from re-sampling and empirical approaches.

With 25 data pairs, the sample curves are more spread out (Fig. 12a), earlier indicated by the higher COV, when compared to the 30 data pairs (Fig. 12b). In case of 35 data pairs (Fig. 12c), there are a few stray sample curves. The 30 data pair set of curves (Fig. 12b) as well as the 35 data pair set of curves (Fig. 12c) are banded closely together, with the latter slightly more spread out. The 95 percent confidence charge weight from re-sampling with 25 data pairs is lower than the empirical one, whereas in the other two cases, the re-sampling approach allows slightly higher charge weight for controlled blasting. As it is proposed to use 30 or more data pairs in re-sampling approach, it can be concluded that the re-sampling approach would facilitate economy in controlled blasting, particularly for the distances higher than $150 \mathrm{~m}$ or so at this site. Similarly, the safe charge weights computed for the various other PPV values of $5 \mathrm{~mm} / \mathrm{s}$, $15 \mathrm{~mm} / \mathrm{s}, 75 \mathrm{~mm} / \mathrm{s}$ and $100 \mathrm{~mm} / \mathrm{s}$, as indicated earlier, are plotted in the Fig. 13.

Considering the Fig. 13 together with Fig. 12d, it may be noted that the re-sampling approach allows for higher charge weight for controlled blasting for limiting PPV of $50 \mathrm{~mm} / \mathrm{sec}$ or higher. Though the exact cross-over has not been identified, from $50 \mathrm{~mm} / \mathrm{s}$ onwards, the safe charge weight from re-sampling is higher than that from the traditional empirical formulation. Thus the proposed approach, by adopting a sound statistical foundation for development of the 95 percent confidence expression, ultimately facilitated higher charge weight allowances (in case of limiting $P P V \geq 50 \mathrm{~mm} / \mathrm{s}$ ) and design of more efficient controlled blasting.

\subsection{Implementation of the proposed methodology for practical design of controlled blasting operation}

The trial blasting should be designed such that the area under consideration is represented well, with around 40 numbers of data sets, for development of the vibration attenuation relationship. First, the suitable equation form applicable for the site should be identified as elucidated in literature [7] from the trial blast data. Thereafter, employing the proposed methodology of re-sampling (each sample having, say, 30 data sets or more), the probability density functions should be established for the parameters of the chosen expression form. The parameter values for the desired confidence level (say, 95\%) can be used to estimate the safe charge weights for the different allowable PPVs corresponding to the different distances (as elucidated in Sect. 3.6). The results can be represented in the form of charts or tables, or both. These charts or tables can be used for reading off the charges for controlled blasting at the site based on the distance and the allowable limiting PPV for the various structures in the vicinity. For different distances from a number of structures, each possibly having different allowable safe PPV limits, there would be a number of charge weights obtained from the tables or charts. For safe controlled blasting, the minimum charge weight among all above should be adopted for the purposes of deep excavation, tunnelling or mining. 


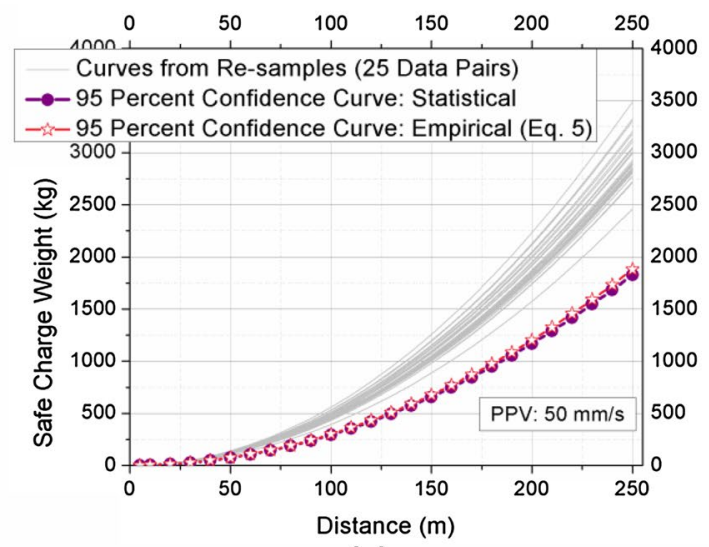

(a)

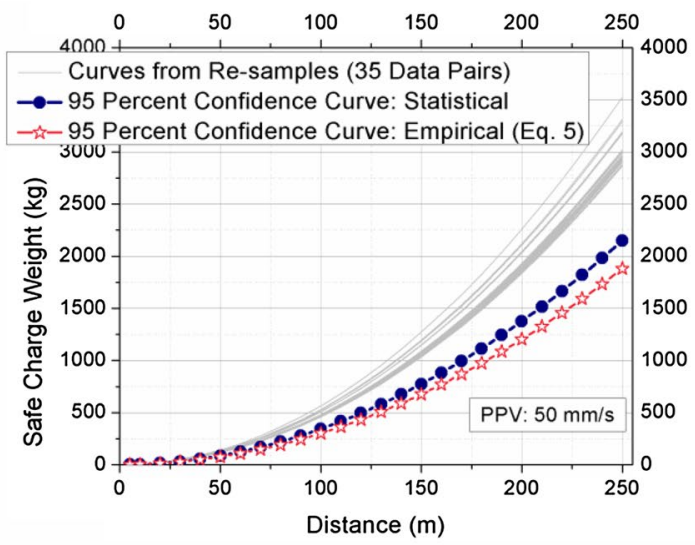

(c)

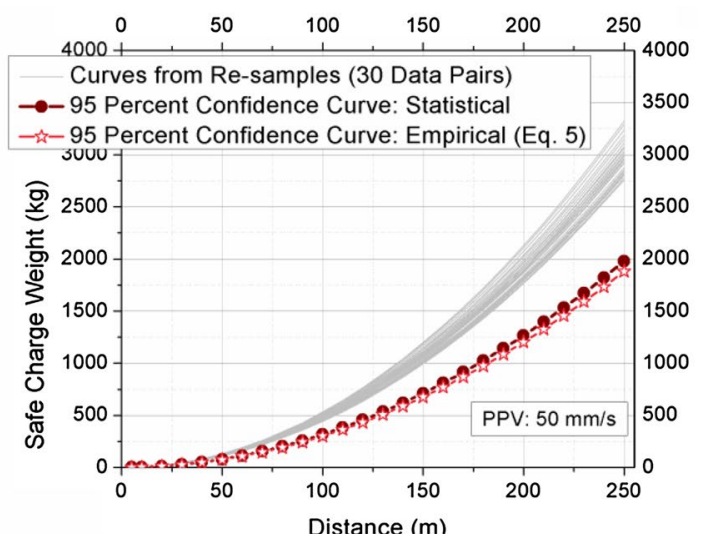

(b)

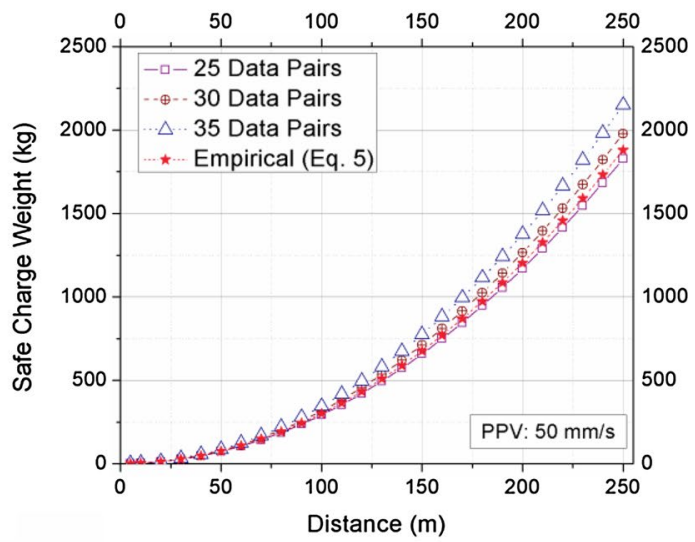

(d)

Fig. 12 Sample expressions superimposed with 95 percent confidence expressions for safe charge weight from empirical and re-sampling approaches. a 25 data pairs, $\mathbf{b} 30$ data pairs, $\mathbf{c} 35$ data pairs, $\mathbf{d}$ overall

\section{Conclusions}

In this article, an approach has been proposed for quantification of the parameter uncertainty of empirical vibration attenuation relationship in case of underground blasts. This is performed using the available trial blast dataset to create around 30 different subsets by re-sampling, estimation of empirical parameters from each of the subsets, and quantification of the parameter uncertainty of the relationship from this suite of estimated empirical parameters. The quantification of uncertainty of the parameters would be indicated by the coefficient of variation of the respective parameters and the overall uncertainty of estimate would be represented by the mean/median of root mean squared error of the re-sampling subsets. Probability density function is fitted to the estimated parameters and using statistical theory, the 95 percent confidence values of the parameters could be established, considering the uncertainties. The empirical expression thus derived would help in estimation of safe charge weights for controlled blasting operations, by addressing the parameter uncertainties on a sound statistical basis. From the study, the following specific conclusions are drawn:

- Different sets of empirical parameters may fit the trial blast data equally well (Eqs. 3 and 4).

- Re-sampling with less data pairs (25) than the suggested 30 numbers led to higher uncertainty of the developed relationship, while using more numbers (35) resulted in reduction of the uncertainty.

- Both the empirical parameters of the power form of expression (Eq. 2) estimated from the re-sampling exercise fit the Normal distribution, as ascertained using the Chi square and Kolmogorov-Smirnov tests.

- The 95 percent confidence expression estimated by the proposed approach could be verified by the blast data from the site, wherein only less than or equal to 5 percent observations exceeded the estimated PPV.

- The traditional empirical 95 percent confidence safe charge expression was observed to be higher (underestimation of PPV) for lower values of limiting PPV $(5 \mathrm{~mm} / \mathrm{s} ; 15 \mathrm{~mm} / \mathrm{s}$ ) when compared to the proposed

\section{SN Applied Sciences}


Fig. 13 Ninety-five percent confidence expressions for safe charge weight from empirical and re-sampling approaches for limiting PPV. a $5 \mathrm{~mm} / \mathrm{s}$, b $15 \mathrm{~mm} / \mathrm{s}, \mathbf{c} 75 \mathrm{~mm} / \mathrm{s}$, d $100 \mathrm{~mm} / \mathrm{s}$

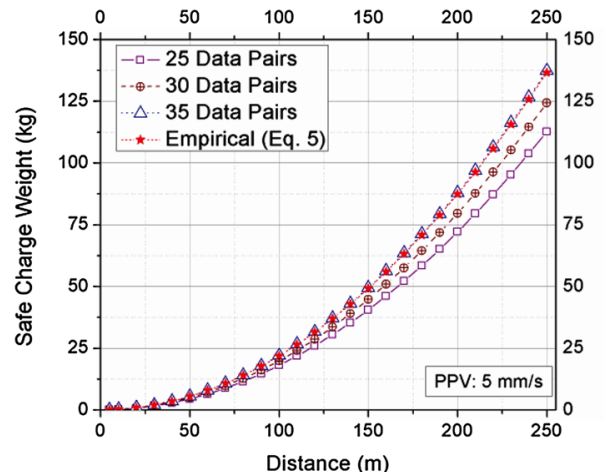

(a)

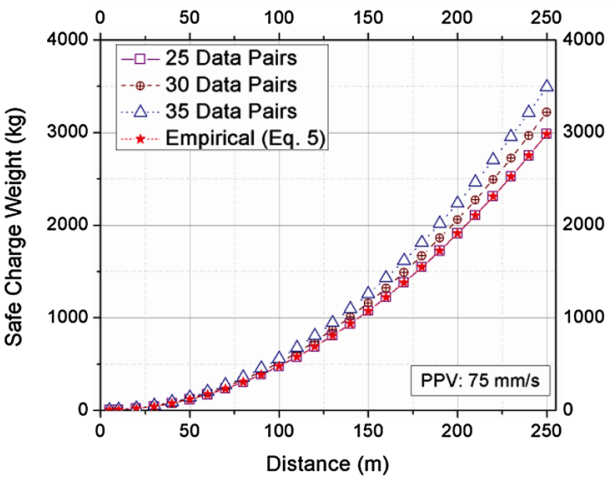

(c)

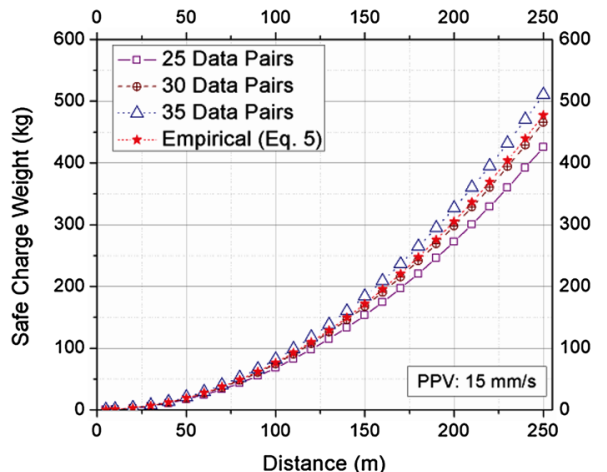

(b)

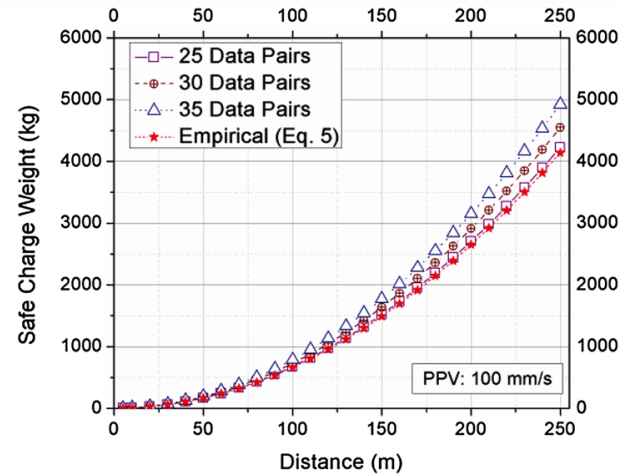

(d) approach. For higher limiting PPV values $(50 \mathrm{~mm} / \mathrm{s}$; $75 \mathrm{~mm} / \mathrm{s} ; 100 \mathrm{~mm} / \mathrm{s}$ ) the PPV was overestimated by the traditional empirical 95 percent confidence expression, resulting in lower safe charges when compared to the estimates by the proposed re-sampling approach.

- Using the traditional empirical 95 percent confidence safe charge expression could be non-conservative in certain cases or uneconomic in certain others owing to the various uncertainties involved. Handling the parameter uncertainties of the empirical expression for underground blast in the proposed re-sampling based approach is advocated for a sound statistical foundation of the analysis.

Addressing the various uncertainties involved in the development of the empirical blast relationship is important for the design of safe controlled blasting operation. The regular industrial practice fails to quantify the uncertainties of the estimated relationships and generally handles it in an ad-hoc manner. In that context, the proposed approach would be extremely useful for quantification of the parameter uncertainties and safe design of controlled blasting operation from limited trial blast data, by accounting for the uncertainties on a firm statistical footing. Especially for the sensitive structures with low limiting values of PPV, conservative safe charge weights could be estimated for the site using the proposed re-sampling approach, where the traditional approach might prove to be non-conservative.

The limitations of this study would include:

- It did not cover the uncertainties in model structure, which would include the expression form for the PPV. Methods to arrive at the best suited expression form for any site have been discussed in literature [7].

- The expression form for scaled distance (SD) was fixed, and uncertainty therein was not examined.

- The contribution of inputs other than the distance and charge weight was not considered; they could include overburden; spacing, number and depth of holes among others and these factors might possibly lead to additional aspects of parameter uncertainties.

- The uncertainty introduced by the technique of evaluation of the empirical parameters was not considered.

Future studies could be directed towards quantification of such uncertainties and accounting for them in estimation of safe charge weight for controlled blasting operations.

Acknowledgements The author sincerely acknowledges the reproduction of the entire experimental data by the authors in the article [3], which were used for this study. The author is indebted to the anonymous reviewers for their critical comments and suggestions in improving the technical content and clarity of presentation in the manuscript. 
Data availability The data used by Agrawal and Mishra [3] in their study have only been used in this discussion. All data are available in the referred article and relevant datasets have been reproduced in Table 1.

\section{Compliance with ethical standards}

Conflict of interest The author declares that there was no known competing interest pertaining to the study presented in this article.

\section{References}

1. Abbaspour $H$, Drebenstedt $C$, Badroddin $M$, Maghaminik A (2018) Optimized design of drilling and blasting operations in open pit mines under technical and economic uncertainties by system dynamic modelling. Int J Min Sci Technol 28:839-848. https://doi.org/10.1016/j.ijmst.2018.06.009

2. Agrawal H, Mishra AK (2018) Probabilistic analysis on scattering effect of initiation systems and concept of modified charge per delay for prediction of blast induced ground vibrations. Measurement 130:306-317. https://doi.org/10.1016/j.measuremen t.2018.08.032

3. Agrawal H, Mishra AK (2019) Modified scaled distance regression analysis approach for prediction of blast-induced ground vibration in multi-hole blasting. J Rock Mech Geotech Eng 11:202-207. https://doi.org/10.1016/j.jrmge.2018.07.004

4. Ayyub B, McCuen RH (1997) Probability, statistics, and reliability for engineers. CRC Press, Boca Raton

5. Ayyub BM, Gupta MM (1998) Uncertainty analysis in engineering and sciences: fuzzy logic, statistics, and neural network approach. Springer, New York

6. Coleman HW, Steele WG (2009) Experimentation, validation, and uncertainty analysis for engineers. Wiley, New Jersey. https://doi. org/10.1002/9780470485682

7. Dauji S (2018) New approach for identification of suitable vibration attenuation relationship for underground blasts. Eng J 22(4):147-159. https://doi.org/10.4186/ej.2018.22.4.147

8. Faradonbeh RS, Armaghani DJ, Majid MZA, Tahir MMD, Murlidhar BR, Monjezi M, Wong HM (2016) Prediction of ground vibration due to quarry blasting based on gene expression programming: a new model for peak particle velocity prediction. Int J Environ Sci Technol 13:1453-1464. https://doi.org/10.1007/ s13762-016-0979-2

9. Goldstein JR, Lutz W, Pflug G (1994) Estimating the uncertainty in population projections by resampling methods. WP-94-106, Int Inst Appl Syst Anal Laxenburg Austria. http://pure.iiasa.ac. at/id/eprint/4106/1/WP-94-106.pdf. Accessed 17 May 2019

10. Haldar A, Mahadevan S (2000) Probability, reliability and statistical methods in engineering design. Wiley, New York

11. Hofer $E$ (2018) The uncertainty analysis of model results: a practical guide. Springer, Basel. https://doi.org/10.1007/978-3-31976297-5

12. Hu Y-M, Liang Z-M, Li B-Q, Yu Z-B (2013) Uncertainty assessment of hydrological frequency analysis using bootstrap method. Math Probl Eng. https://doi.org/10.1155/2013/724632

13. Kalayki U, Ozer U (2016) Selection of site specific vibration equation by using analytical hierarchy process in a quarry. Environ Impact Assess Rev 56:50-59. https://doi.org/10.1016/j. eiar.2015.09.004

14. Khandelwal M, Singh TN (2009) Prediction of blast-induced ground vibration using artificial neural network. Int J Rock Mech Min Sci 46:1214-1222. https://doi.org/10.1016/j.ijrmm s.2009.03.004
15. Li Y, Simmonds D, Reeve D (2008) Quantifying uncertainty in extreme values of design parameters with resampling techniques. Ocean Eng 35:1029-1038. https://doi.org/10.1016/j. oceaneng.2008.02.009

16. Lombardi AM (2017) The epistemic and aleatory uncertainties of the ETAS-type models: an application to the Central Italy seismicity. Nat Sci Rep 7(11812):1-9. https://doi.org/10.1038/s4159 8-017-11925-3

17. Longjun D, Xibing L, Ming X, Qiyue $L$ (2011) Comparisons of random forest and support vector machine for predicting blasting vibration characteristic parameters. Proc Eng 26:1772-1781. https://doi.org/10.1016/j.proeng.2011.11.2366

18. McMullan S, Collins GS (2019) Uncertainty quantification in continuous fragmentation airburst models. Icarus 327:19-35. https ://doi.org/10.1016/j.icarus.2019.02.013

19. Modarres $M$, Kaminskiy $M$, Krivtsov V (2010) Reliability engineering and risk analysis. CRC Press, Boca Raton

20. Mohamadnejad M, Gholami R, Ataei M (2012) Comparison of intelligence science techniques and empirical methods for prediction of blasting vibrations. Tunn Undergr Space Technol 28:238-244. https://doi.org/10.1016/j.tust.2011.12.001

21. Monjezi M, Ahmadi M, Sheikhan M, Bahrami A, Salimi AR (2010) Predicting blast-induced ground vibration using various types of neural networks. Soil Dyn Earthq Eng 30(11):1233-1236. https ://doi.org/10.1016/j.soildyn.2010.05.005

22. Monjezi M, Ghafurikalajahi M, Bahrami A (2011) Prediction of blast-induced ground vibration using artificial neural networks. Tunn Undergr Space Technol 26:46-50. https://doi. org/10.1016/j.tust.2010.05.002

23. Monjezi M, Baghestani M, Faradonbeh RS, Saghand MP, Armaghani DJ (2016) Modification and prediction of blast-induced ground vibrations based on both empirical and computational techniques. Eng Comput 32(4):717-728. https://doi. org/10.1007/s00366-016-0448-z

24. Mottahedi A, Sereshki F, Atael M (2017) Development of overbreak prediction models in drill and blast tunneling using soft computing methods. Eng Comput 34(1):45-58. https://doi. org/10.1007/s00366-017-0520-3

25. Murmu S, Maheshwari P, Verma HK (2018) Empirical and probabilistic analysis of blast-induced ground vibrations. Int J Rock Mech Min Sci 103:267-274. https://doi.org/10.1016/j.ijrmm S.2018.01.038

26. Naik B, Rilett LR, Appiah J, Walubita LF (2018) Resampling methods for estimating travel time uncertainty: application of the gap bootstrap. Transp Res Rec. https://doi.org/10.1177/03611 98118792124

27. Ng JL, Aziz SA, Huang YF, Mirzae M, Wayayok A, Rowshor MK (2019) Uncertainty analysis of rainfall depth duration frequency curves using the bootstrap resampling technique. J Earth Syst Sci. https://doi.org/10.1007/s12040-019-1154-1

28. Nguyen H, Drebenstedt C, Bui X-N, Bui DT (2019) Prediction of blast-induced ground vibration in an open-pit mine by a novel hybrid model based on clustering and artificial neural network. Nat Resour Res. https://doi.org/10.1007/s11053-019-09470-z

29. Ragam P, Nimaje DS (2018) Evaluation and prediction of blastinduced peak particle velocity using artificial neural network: a case study. Noise Vib Worldw 49(3):111-119. https://doi. org/10.1177/0957456518763161

30. Ray S, Dauji S (2019) Ground vibration attenuation relationship for underground blast: a case study. J Inst Eng Ser A. https://doi. org/10.1007/s40030-019-00382-y

31. Ray S, Dauji S, Dutta D, Bhargava K (2018) Development of empirical model for estimation of peak particle velocity for underground blasts. In: Singh SB (ed) Advances in concrete, structural and geotechnical engineering. Bloomsbury Publishing India Pvt. Ltd., New Delhi, pp 196-200 
32. Rustomji P, Wilkinson SN (2008) Applying bootstrap resampling to quantify uncertainty in fluvial suspended sediment loads estimated using rating curves. Water Resour Res 44:1-12. https:// doi.org/10.1029/2007WR006088

33. Saadat M, Khandelwal M, Monjezi M (2014) An ANN-based approach to predict blast-induced ground vibration of Gol-EGohar iron ore mine, Iran. J Rock Mech Geotech Eng 6:67-76. https://doi.org/10.1016/j.jrmge.2013.11.001

34. Sharififar A, Sarmadian F, Minasny B (2019) Mapping imbalanced soil classes using Markov chain random fields models treated with data resampling technique. Comput Electron Agric 159:110-118. https://doi.org/10.1016/j.compag.2019.03.006

35. Shaw BD (2017) Uncertainty analysis of experimental data with R. CRC Press, Boca Raton

36. Sikorska AE, Montanari A, Koutsoyiannis D (2014) Estimating the uncertainty of hydrological predictions through datadriven resampling techniques. J Hydrol Eng ASCE. https://doi. org/10.1061/(ASCE)HE.1943-5584.0000926

37. Stewart MG, Netherton MD (2019) A probabilistic riskacceptance model for assessing blast and fragmentation safety hazards. Reliab Eng Syst Saf. https://doi.org/10.1016/j. ress.2019.05.004

38. Tripathy GR, Shirke RR (2015) Underwater drilling and blasting for hard rock dredging in Indian ports: a case study. Aquat Proc 4:248-255. https://doi.org/10.1016/j.aqpro.2015.02.034

39. Tripathy GR, Shirke RR, Kudale MD (2016) Safety of engineered structures against blast vibrations: a case study. J Rock Mech Geotech Eng 8(2):248-255. https://doi.org/10.1016/j.jrmge .2015.10.007

40. Tung Y-K, Yen B-C (2005) Hydrosystems engineering uncertainty analysis. McGraw Hill, New York

Publisher's Note Springer Nature remains neutral with regard to jurisdictional claims in published maps and institutional affiliations. 